\title{
Intermediate-term results of repair for aortic, neoaortic, and truncal valve insufficiency in children
}

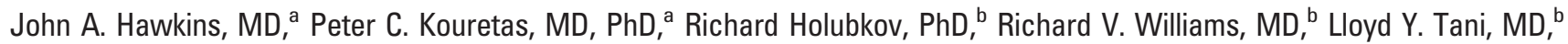
Jason T. Su, DO, ${ }^{b}$ Linda M. Lambert, RN, ${ }^{a}$ Christopher R. Mart, MD ${ }^{\mathrm{b}}$, Michael D. Puchalski, MD, ${ }^{\mathrm{b}}$ and L. LuAnn Minich, MD

Objective: Repair of aortic valve insufficiency is difficult, and durability is relatively unknown in children. This study evaluates the intermediate-term results of repair of the systemic semilunar valve, including the native aortic valve, neoaortic valve (anatomic pulmonary), and truncal valve.

Methods: We reviewed the records of 54 children (aged 2 days to 18 years) who underwent repair of the functional aortic valve for moderate or greater insufficiency from 1991 to 2005. Valve anatomy was tricuspid aortic in 26 patients, bicuspid aortic in 11 patients, tricuspid neoaortic in 9 patients, bicuspid neoaortic in 1 patient, and truncal valve in 7 patients. Multiple surgical techniques were used in most of the 54 patients, including leaflet plication in 17 , leaflet repair in 15 , commissuroplasty in 32, pericardial cusp augmentation in 8 , and sinus of Valsalva reduction in 3.

Results: There was 1 early death and no late deaths. Actuarial freedom from reoperation was $68 \%$ at 5 years and $58 \%$ at 10 years. Freedom from aortic valve replacement was $82 \%$ at 5 years and $73 \%$ at 10 years. Duration of cardiopulmonary bypass was the most significant risk factor for reoperation with multivariate analysis. Of the 40 patients who have not undergone reoperation, 37 have had follow-up echocardiograms with the latest study $(4.5 \pm 4.2$ years $)$ demonstrating trace to $1+$ insufficiency in 23 patients, 1 to $2+$ in 12 patients, 2 to $3+$ in 1 patient, and 3 to $4+$ in 1 patient.

Conclusion: Repair of the insufficient systemic semilunar valve offers acceptable 10 -year freedom from reoperation and functional results, and should be considered for most children.

From the Division of Cardiothoracic Surgery $^{\mathrm{a}}$ and Cardiology, ${ }^{\mathrm{b}}$ Departments of Surgery and Pediatrics, Primary Children's Medical Center, and the University of Utah, Salt Lake City, Utah.

Presented at the Thirty-second Annual Meeting of the Western Thoracic Surgical Association, Sun Valley, Idaho, June 2124, 2006

Received for publication June 20, 2006; revisions received Oct 31, 2006; accepted for publication Nov 6, 2006.

Address for reprints: John A. Hawkins, MD, Cardiothoracic Surgery, Primary Children's Medical Center, 100 North Medical Drive, Salt Lake City, UT 84113 (E-mail: jhawkins@ hsc.utah.edu).

J Thorac Cardiovasc Surg 2007;133:1311-7

$0022-5223 / \$ 32.00$

Copyright (C) 2007 by The American Association for Thoracic Surgery

doi:10.1016/j.jtcvs.2006.11.051

$\mathrm{T}$ The timing of surgical intervention and the optimal surgical approach for insufficiency of the systemic semilunar valve in infants and children are difficult issues. Although repair of aortic insufficiency in adults has gained popularity over the last 10 years, there is limited experience in children and long-term results are unknown. The ability to repair an insufficient valve may be even more important for the growing child to avoid the need to replace or up-size a prosthetic valve or allograft. In addition, valve repair avoids the need for anticoagulation, which can be more difficult to achieve and associated with higher risk of complications in the pediatric population.

This study examines our intermediate-term results with repair of native aortic valves, truncal valves, and anatomic pulmonary valves functioning as systemic neoaortic valves, such as those after the arterial switch for transposition, singleventricle palliation, or the pulmonary autograft (Ross) procedure. We also sought to determine risk factors for predicting failure of valve repairs.

\section{Patients and Methods \\ Patients}

The database of Cardiothoracic Surgery at Primary Children's Medical Center and the University of Utah was reviewed to identify children aged less than 18 years who had at least 


\section{Abbreviations and Acronyms}

TEE $=$ transesophageal echocardiography

$3+$ (moderate to severe) insufficiency of the aortic, truncal, or systemic semilunar valve and underwent operation between July 1991 and January 2006. Of these patients, those who underwent repair of the systemic semilunar valve form the basis for this study. The institutional review board at Primary Children's Medical Center and the University of Utah approved this retrospective review. Records were reviewed to obtain age, weight, additional cardiac anomalies, valve morphology, operative times, additional procedures, techniques used, presence and degree of left ventricular outflow tract obstruction, and details at reoperation. End points included reoperation on the valve, late valve function defined by echocardiography, and death.

\section{Echocardiography}

Complete two-dimensional, Doppler, and M-mode transthoracic echocardiograms were performed preoperatively to evaluate cardiac anatomy, systemic semilunar valve stenosis, and regurgitation. Stenosis was evaluated by measuring the peak instantaneous gradient across the systemic semilunar valve obtained using continuous-wave Doppler interrogation from all available views. Valve regurgitation was graded from trace to $4+$ using a combination of previously described measurements, including the ratio of diameter of the regurgitant color Doppler jet to the aortic annulus diameter from the parasternal long-axis view, the ratio of the area of the color Doppler regurgitant jet to the area of the aortic annulus from the parasternal short-axis view, the presence or absence of holodiastolic flow reversal in the descending aorta below the diaphragm, and the presence or absence of left ventricular enlargement measured by M-mode. ${ }^{1}$

Additional guidance and assessment of the valve morphology was performed by transesophageal echocardiography (TEE) in the operating room both before and after surgical repair. TEE imaging and color Doppler allowed further assessment of leaflet abnormalities along with localization of coaptation abnormalities and specific areas of regurgitant jets. The short-axis view was routinely used to measure and localize the area of the regurgitant jet for grading purposes and direction of specific leaflet therapies.

\section{Operative Techniques}

All patients underwent operation with moderate hypothermia $\left(24^{\circ} \mathrm{C}-28^{\circ} \mathrm{C}\right)$ and blood cardioplegia. Cardioplegia was routinely reinfused at 20- to 30-minute intervals, with retrograde or antegrade direct coronary instillation. Techniques used to repair the valve varied according to the anatomy of the valve and the cause of insufficiency. Each valve was inspected to determine the anatomy and cause of insufficiency and the anatomic defects at 3 levels: the annulus, valve leaflets, and sinuses and sinotubular junction. Attempts were made to normalize the anatomy as much as possible at all 3 levels, depending on the anatomic abnormality. Annular dilation with failure of cusp coaptation was corrected by circumferential annuloplasty techniques ${ }^{2}$ or subcommissural plication in the interleaflet triangle to reduce the annulus size and improve coaptation. ${ }^{3}$ The leaflets were evaluated for size, leaflet damage or defects, and coaptation area. Defects or damage to valve leaflets were repaired by previously described techniques. ${ }^{4,5}$ Elongated or prolapsing leaflets were repaired by plication using the technique described by Trusler and colleagues. ${ }^{6}$ Inadequate leaflet tissue was augmented using autologous, glutaraldehydetreated pericardium. ${ }^{7}$ Sinus enlargement or sinotubular junction enlargement that was thought to be contributing to valve insufficiency was treated with sinus reduction techniques. ${ }^{8}$

\section{Follow-up}

All 54 patients underwent follow-up by their individual cardiologist, and information regarding reintervention and survival was obtained on all patients between March and June 2006. Postoperative echocardiography was used to evaluate postoperative results, and identical criteria were used to evaluate valve insufficiency or stenosis as used on preoperative evaluation.

Valve-related reintervention was defined as any reoperation for recurrent or persistent systemic semilunar valve regurgitation. The most common indications for reintervention, determined by the child's cardiologist, were $\geq 3+$ systemic semilunar valve insufficiency accompanied by symptoms, systemic ventricular enlargement, or reduced systemic ventricular function.

\section{Statistical Methods}

Normally distributed data are presented as mean \pm standard deviation. Non-normally distributed data are described as median and range. Survival and event-free survival were calculated and presented in Kaplan-Meier format. ${ }^{9}$ Factors associated with reintervention for late significant valve insufficiency were analyzed in a univariate analysis using Cox's proportional hazard model. ${ }^{10}$ After this univariate analysis, factors that showed a trend toward influencing the need for later reintervention $(P<.2)$ were entered into a multivariate forward stepwise regression analysis. Factors analyzed included age at operation, date of operation, age less than 4 years, valve type, need for additional procedures, anatomic diagnosis, previous or concurrent left ventricular outflow tract surgery, valve anatomy and number of cusps, crossclamp time, cardiopulmonary bypass duration, and repair techniques used.

\section{Results}

A total of 93 patients underwent operation and had at least $3+$ systemic semilunar valve insufficiency during the study period. This included 39 patients $(39 / 93,42 \%)$ who underwent valve replacement and 54 patients $(54 / 93,58 \%)$ who underwent their first operation for repair of at least $3+$ systemic semilunar valve insufficiency and form the basis for this study. Diagnoses for the patients undergoing repair are listed in Table 1. The indication for operation was solely insufficiency of the semilunar systemic valve in 17 patients and a combination of valve insufficiency and other anomalies requiring surgical attention in the remaining 37 patients. The insufficient valve was morphologically a tricuspid aortic valve in 26 patients, a bicuspid aortic valve in 11 patients, a tricuspid neoaortic (anatomic pulmonary) valve functioning in situ in 6 patients, a tricuspid neoaortic valve 
TABLE 1. Patient diagnosis associated with valve insufficiency

\begin{tabular}{lc}
\hline Diagnosis & No. (\%) \\
\hline Aortic valve prolapse with ventricular septal defect & $15(28)$ \\
Post-balloon valvuloplasty/aortic valvotomy & $11(20)$ \\
Truncus arteriosus & $7(13)$ \\
Rheumatic heart disease & $6(11)$ \\
Subaortic stenosis & $4(7)$ \\
Transposition of great arteries s/p arterial switch & $4(7)$ \\
$\quad$ procedure & \\
Previous Ross procedure & $3(6)$ \\
Previous Damus-Kaye-Stansel connection & $2(4)$ \\
Hypoplastic left heart syndrome & $1(2)$ \\
Isolated congenital bicuspid aortic valve & $1(2)$ \\
Total & $54(100)$ \\
\hline
\end{tabular}

functioning as an autltograft in 3 patients, a bicuspid systemic neoaortic valve functioning in situ in 1 patient, and a truncal valve in 7 patients. Of the 7 truncal valves, 5 were quadricuspid and 2 were tricuspid. Multiple techniques were used in most patients $(30 / 54,56 \%)$ and included commissuroplasty $^{3}$ in 32 , leaflet plication ${ }^{6}$ in 17 , leaflet repair ${ }^{4,5}$ in 15 , cusp augmentation ${ }^{7}$ in 8 , circumferential annuloplasty ${ }^{2}$ in 7 , and sinus of Valsalva reduction plasty ${ }^{8}$ in 3 . Patient age at operation ranged from 4 days to 18 years (mean $=8.5 \pm 6.5$ years) and included 10 infants less than 1 year of age, 8 patients aged between 1 and 4 years, 11 patients aged between 4 and 10 years, and 25 patients aged between 10 and 18 years.

Hospital mortality over the 15 -year study period was 1 of 54 patients $(1.9 \%)$. The single operative death was from multisystem organ failure 3 weeks postoperatively in a neonate who underwent aortic valve repair after an arterial switch procedure and had early severe aortic valve insuffi- ciency. Follow-up ranged from 4 months to 15 years and was a mean of $76 \pm 58$ months. No late deaths occurred, and actuarial survival including the 1 early death is $98 \%$ at 15 years.

Thirteen of the 54 patients required reintervention (13/ 54, 23\%) $48 \pm 28$ months after aortic valve repair. No patient required aortic valve replacement during the same hospitalization after aortic valve repair. Reintervention was for pure systemic semilunar valve regurgitation of $\geq 3+$ with evidence of left ventricular enlargement and/or symptoms in 11 patients and for mixed aortic insufficiency and aortic stenosis in 2 patients. Both patients with mixed stenosis and insufficiency had aortic insufficiency associated with leaflet avulsion after balloon valvuloplasty for aortic stenosis. ${ }^{4}$ Reintervention consisted of re-repair in 5 patients, aortic valve replacement with a mechanical prosthetic valve in 4 patients, and pulmonary autograft aortic valve replacement (Ross procedure) in 4 patients. There were no early or late deaths after reoperation. The 8 aortic valve replacements occurred $53+31$ months after repair. The actuarial rate of reoperation for valve-related causes including replacement or re-repair and the actuarial freedom from valve replacement are shown in Figure 1. Overall, reoperation free slurvival was $98 \%$ at 1 year, $68 \%$ at 5 years, and $58 \%$ at 10 years. Freedom from aortic valve replacement was $100 \%$ at 1 year, $82 \%$ at 5 years, and $67 \%$ at 10 years.

Of the 5 patients who have undergone re-repair, 1 has undergone a third repair and now has trace to $1+$ aortic insufficiency, 3 have only $1+$ aortic insufficiency, and 1 has 2 to $3+$ insufficiency but is asymptomatic with moderate left ventricular enlargement and has not undergone reoperation for the third time to date. Of the 40 patients who have not undergone reoperation, 37 had follow-up echocardiograms $4.5 \pm 4.2$ years after surgery with trace to $1+$ systemic semilunar valve insufficiency in 23 patients, 1 to

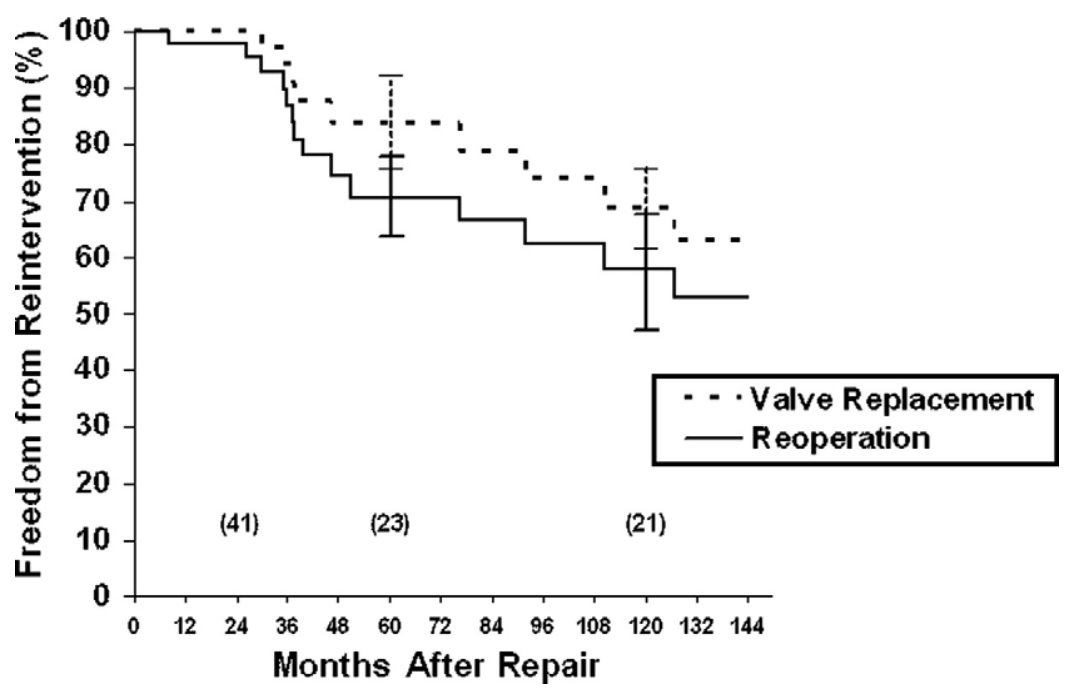

Figure 1. Actuarial freedom from reintervention for aortic valve replacement or reoperation for any valve-related cause after first repair of moderate or greater insufficiency of aortic, neoaortic, or truncal valves in $\mathbf{5 4}$ children. Patients free of aortic valve replacement (dashed line); patients free of any reintervention, valve replacement, or re-repair (solid line); 67\% confidence intervals (error bars). The number of patients (in parentheses) followed at that interval. 
TABLE 2. Univariate analysis of risk factors leading to reintervention after repair of aortic, truncal, or neoaortic valve insufficiency

\begin{tabular}{lcll}
\hline Factor & $\begin{array}{c}\boldsymbol{P} \\
\text { value }\end{array}$ & $\begin{array}{c}\text { Relative } \\
\text { risk }\end{array}$ & $\begin{array}{c}\text { 95\% CI for } \\
\text { relative risk }\end{array}$ \\
\hline Bypass time & .013 & 1.015 & $(1.003-1.027)$ \\
Year of procedure & .018 & 5.61 & $(1.35-23.38)$ \\
Nonaortic valve & .057 & 3.51 & $(0.96-12.81)$ \\
Sinus reduction & .087 & 7.27 & $(0.75-70.65)$ \\
Crossclamp time & .16 & 1.017 & $(0.993-1.042)$ \\
Complex procedures & .20 & 3.03 & $(0.85-10.79)$ \\
Annuloplasty & .34 & 2.13 & $(0.45-10.07)$ \\
Leaflet repair & .39 & 1.59 & $(0.55-4.59)$ \\
Additional procedures & .48 & 0.63 & $(0.17-2.28)$ \\
Trusler repair & .53 & 0.71 & $(0.24-2.08)$ \\
Commissuroplasty & .53 & 1.41 & $(0.48-4.13)$ \\
Leaflet augmentation & .56 & 0.044 & - \\
Age <4 y & .58 & 1.39 & $(0.43-4.45)$ \\
Tricuspid valve morphology & .59 & 0.73 & $(0.23-2.33)$ \\
LV0T surgery & .61 & 0.72 & $(0.20-2.59)$ \\
Age & .75 & 0.99 & $(0.91-1.07)$ \\
\hline
\end{tabular}

$\mathrm{Cl}$, Confidence interval; $L V O T$, left ventricular outflow tract.

$2+$ in 12 patients, 2 to $3+$ in 1 patient, and $\geq 3+$ in 1 patient. Residual Doppler aortic gradients were less than 20 $\mathrm{mm} \mathrm{Hg}$ in 29 patients, 20 to $40 \mathrm{~mm} \mathrm{Hg}$ in 6 patients, and 43 $\mathrm{mm} \mathrm{Hg}$ in 1 patient.

Univariate analyses of risk factors associated with reintervention are listed in Table 2. The most significant factors associated with reintervention were longer cardiopulmonary bypass times $(P=.013)$ and year of procedure after 2000 $(P=.018)$. We did not find complex repairs (vs simple repairs), number of valve cusps, anatomic type of valve, anatomic diagnosis, specific repair technique, or age to be an independent predictor of reintervention. Multiple stepwise forward regression analysis showed that only duration of bypass was an independent predictor of reintervention.

\section{Discussion}

Insufficiency or leakage of an aortic or systemic semilunar valve is an infrequent, but challenging, problem in children. Although repair of aortic valve insufficiency in adults has increased in selected patients in recent years, ${ }^{11}$ repair of these valves in children remains relatively uncommon. This is likely the result of the complex and variable anatomy of the semilunar valve in congenital heart disease. Our series demonstrates that despite the anatomic variability, there remains a definite potential for aortic or systemic semilunar valve repair in a heterogeneous group of patients. Careful application of repair techniques results in long-term durability with less than half requiring reoperation at 10 years.

Previous reports of repair of aortic insufficiency in children are relatively few and have conflicting results. Hasaniya and associates ${ }^{12}$ reported a $47 \%$ reoperation rate at 6 years in 21 children after aortic valve repair and did not recommend repair as a viable alternative for children with aortic insufficiency. Tweddell and associates ${ }^{13}$ reported their experience with aortic valve repair in a group of heterogenous patients. Freedom from reoperation at 10 years for the group requiring "complex" repairs (analogous to those in this report) was $44 \%$. Although others have reported long-term results of repair of aortic insufficiency in young patients, most have combined both adult and pediatric patients, making careful analysis of results in the infant and young child difficult. ${ }^{14-17}$

The repair of the aortic, truncal, or neoaortic valve needs to be individualized to the specific valve anatomy and disease, but the approach can be standardized to systematically evaluating the annulus, the leaflets, and the sinuses and sinotubular junction. ${ }^{18}$ Once the abnormal anatomy is clearly understood at each level, individual techniques can be used to restore valve competence. Annular enlargement is dealt with by commissuroplasty ${ }^{3}$ or circumferential annuloplasty ${ }^{2}$ to restore a normal or near normal annular size. We have found circumferential annuloplasty to be particularly useful when repairing neoaortic regurgitation after the pulmonary autograft (Ross) procedure. ${ }^{19}$ The subsequent circumferential suture line with this technique may inhibit annular growth in the child, and we attempt to minimize this risk by using an absorbable stitch (polydioxanone). Regardless, careful follow-up is needed because long-term growth of the annulus with this technique is unknown and left ventricular outflow tract obstruction may develop. Leaflet abnormalities can be repaired by direct suture, patch, reattachment, or even cusp augmentation with pericardium. Cusp reattachment and repair with pericardium are particularly applicable in patients with aortic insufficiency after balloon valvuloplasty. ${ }^{4,8}$ Cusp augmentation is useful for centrally located insufficiency from cusp thickening and retraction, characteristic of rheumatic aortic insufficiency. Cusp augmentation may also be applicable when 1,2, or all leaflets appear to have an inadequate surface area for coaptation. We have found glutaraldehyde-treated autologous pericardium to work best, but others have found untreated autologous or bovine pericardium to be equally efficacious. ${ }^{20,21}$ The immediate results of pericardial augmentation are good, but the long-term durability and its potential for growth are unknown. This approach will allow many, if not most, children to have valve repair rather than replacement. It also has resulted in 5- and 10-year freedom from reoperation rates in our series of $89 \%$ and $64 \%$, respectively, comparable to rates reported in adults in a recent review. ${ }^{11}$

In this study, the length of operation was found to be an independent predictor of the subsequent need for reintervention for systemic semilunar valve insufficiency. Others 
have found that the amount of residual regurgitation when the patient either leaves the operating room or the hospital is strongly predictive of the need to reoperate. ${ }^{3,12} \mathrm{We}$ did not analyze this as a risk factor because, in our practice, patients with more than mild insufficiency were returned to bypass and further repair was performed to achieve competence. The longer duration of bypass as a major factor associated with reintervention may reflect more complex repairs that are more likely to fail. It may also indicate that as our experience has grown, we have extended indications for valve repair into an area in which success is not as likely or as durable.

Although non-aortic valves, such as truncal valves, bicuspid valves, or pulmonic valves functioning as neoaortic valves, approach significance $(P=.057)$ as a factor predicting the need for reintervention in the univariate analysis, they were not independent predictors in the multivariate model. No particular technique was associated with reintervention, implying that the specific method of repair is probably not as important as the valve itself for determining the need for reoperation.

There are few reports of operation for neoaortic regurgitation after the arterial switch, and in the largest series to date, 13 of 16 patients had aortic valve replacement and only 3 patients had repair, with 1 failure. ${ }^{22}$ Despite this, we and others would argue that repair should be attempted in the majority of patients with significant neoaortic insufficiency after the arterial switch, unless there is significant root enlargement and root replacement is warranted. ${ }^{23}$ Truncal valve repair has been reported in several small series with mixed results. ${ }^{24-26}$ Similarly, others have shown that the neoaortic valve can be repaired after the Ross procedure. ${ }^{19,27}$ To our knowledge, repair of anatomic pulmonary valves in a single-ventricle circulation after a DamusKaye-Stansel or Norwood-type procedure has not been reported to date. The 3 patients in this series have all been followed less than 2 years, so it is impossible to draw conclusions about long-term durability of the neoaortic valve in the single-ventricle situation, although it should not be significantly different than the situation after the arterial switch procedure for transposition of the great arteries. Despite the unknown durability, we believe that the neoaortic or truncal valve functioning in the systemic circulation should undergo attempts at repair, because our early and mid-term results are promising and there is no option of a pulmonary autograft procedure in these subgroups.

This study is limited by several factors. First, this is a relatively large number of pediatric patients with systemic semilunar valve insufficiency, but the numbers of patients in each diagnostic group are small. Thus, specific recommendations or conclusions regarding the advisability of repair for specific lesions or valve morphology type cannot be made. This heterogeneity and small sample size also make inferences regarding the efficacy of specific valve repair techniques difficult. Although this series represents a relatively large number of patients over a 15 -year period, the type of valve considered for repair has evolved over the years. Early in the experience, most patients had aortic insufficiency after balloon valvuloplasty or associated with a ventricular septal defect. More recently, repair has been attempted in any child with systemic semilunar valve insufficiency, including hypoplastic left heart syndrome, postRoss procedure, truncus arteriosus, rheumatic heart disease, or even a previous valve repair. This change in patient selection along with a shorter duration of follow-up for the more complex cases make long-term evaluation of current techniques and indications difficult. In addition, there is no way to compare the groups who had replacement without an attempt at repair in the early part of the series with those who were routinely repaired toward the end of the series.

\section{Conclusions}

We demonstrated a diverse group of pediatric patients with aortic, neoaortic, or truncal valve insufficiency who underwent repair of the existing semilunar valve with acceptable intermediate-term results. An individualized approach tailored to the anatomic abnormalities noted at the annular, valvar, and sinotubular regions can be effective, with less than half the patients requiring reoperation in the decade after repair.

\section{References}

1. Tani LY, Minich LL, Day RW, Orsmond GS, Shaddy RE. Doppler evaluation of aortic regurgitation in children. Am J Cardiol. 1997;80: 927-31.

2. Izumoto H, Kawazoe K, Kawase T, Kim H. Subvalvular circular annuloplasty as a component of aortic valve repair. J Heart Valve Dis. 2002;11:383-5.

3. Cosgrove DM, Rosenkranz ER, Hendren WG, Bartlett JC, Stewart WJ. Valvuloplasty for aortic insufficiency. J Thorac Cardiovasc Surg. 1991;102:571-7.

4. Hawkins JA, Minich LL, Shaddy RE, Tani LY, Orsmond GS, Sturtevant JE, et al. Aortic valve repair and replacement after balloon aortic valvuloplasty in children. Ann Thorac Surg. 1996;61:1355-8.

5. Fraser CD, Cosgrove DM. Surgical techniques for aortic valvuloplasty. Tex Heart Inst J. 1994;21:305-9.

6. Trusler GA, Moes CAF, Kidd BSL. Repair of ventricular septal defect with aortic insufficiency. J Thorac Cardiovasc Surg. 1973;66:394-403.

7. Duran CMG, Gometza B, Shahid M, Al-Halees Z. Treated bovine and autologous pericardium for aortic valve reconstruction. Ann Thorac Surg. 1998;66:S166-9.

8. Bacha EA, Satou GM, Moran AM, Zurakowski D, Marx GR, Keane $\mathrm{JF}$, et al. Valve-sparing operation for balloon-induced aortic regurgitation in congenital aortic stenosis. J Thorac Cardiovasc Surg. 2001; 122:162-8.

9. Kaplan EL, Meier P. Non-parametric estimation from incomplete observations. J Am Stat Soc. 1958;53:457-81

10. Cox DR. Regression model and life tables. J R Stat Soc. 1972;B34: 187-220.

11. Carr JA, Savage EB. Aortic valve repair for aortic insufficiency in adults: a contemporary review and comparison with replacement techniques. Eur J Cardiothorac Surg. 2004;25:6-15. 
12. Hasaniya N, Gundry SR, Razzouk AJ, Mulla N, Bailey LL. Outcome of aortic valve repair in children with congenital aortic valve insufficiency. J Thorac Cardiovasc Surg. 2004;127:970-4.

13. Tweddell JS, Pelech AN, Frommelt PC, Jaquiss RDB, Hoffman GM, Mussatto KA, et al. Complex aortic valve repair as a durable and effective alternative to valve replacement in children with aortic valve disease. J Thorac Cardiovasc Surg. 2005;129:551-8.

14. Rao V, Van Arsdell GS, David TE, Azakie A, Williams WG. Aortic valve repair for adult congenital heart disease. A 22-year experience. Circulation. 2000;102(suppl III):III-40-3.

15. Izumoto H, Kawazoe K, Ishibashi K, Kin H, Kawase T, Nakajima T, et al. Aortic valve repair in dominant aortic regurgitation. Jpn J Thorac Cardiovasc Surg. 2001;49:355-9.

16. Duran CMG, Gometza B. Aortic valve reconstruction in the young. J Card Surg. 1994;9:204-8.

17. Haydar HS, He GW, Hovaguimian H, McIrvin DM, King DH, Starr A. Valve repair for aortic insufficiency: surgical classification and techniques. Eur J Cardiothorac Surg. 1997;11:258-65.

18. Langer F, Aicher D, Kissinger A, Wendler O, Lausberg H, Fies R, et al. Aortic valve repair using a differentiated surgical strategy. Circulation. 2004;110(Suppl II):II-67-73.

19. Elkins RC, Lane MM, McCue C. Pulmonary autograft reoperation: incidence and management. Ann Thorac Surg. 1996;62:450-5.

20. Kolangos A, Beghetti M, Baldovinos A, et al. Aortic valve repair by cusp extension with the use of fresh autologous pericardium in children with rheumatic aortic insufficiency. $J$ Thorac Cardiovasc Surg. 1999;118:225-36.

21. Al Halees Z, Al Shahid M, Al Sanei A, Sallehuddin A, Duran C. Up to 16 years follow-up of aortic valve reconstruction with pericardium: a stentless readily available cheap valve? Eur J Cardiothorac Surg. 2005;28:200-5.

22. Losay J, Touchot A, Capderou A, Piot JD, Belli E, Planché C, et al. Aortic valve regurgitation after arterial switch operation for transposition of the great arteries. J Am Coll Cardiol. 2006;47:2057-62.

23. Imamura M, Drummond-Webb JJ, McCarthy JF, Mee RBB. Aortic valve repair after arterial switch operation. Ann Thorac Surg. 2000; 69:607-8.

24. Black MD, Adatia I, Freedom RM. Truncal valve repair: initial experience in neonates. Ann Thorac Surg. 1998;65:1737-40.

25. Mavroudis C, Backer CL. Surgical management of severe truncal insufficiency: experience with truncal valve remodeling techniques. Ann Thorac Surg. 2001;72:396-400.

26. McElhinney DB, Reddy VM, Rajasinghe HA, Mora BN, Silverman NH, Hanley FL. Trends in the management of truncal valve insufficiency. Ann Thorac Surg. 1998;65:517-20.

27. Brown JW, Ruzmetov M, Fukui T, Rodefeld MD, Mahomed Y, Turrentine MW. Fate of the autograft and homograft following Ross aortic valve replacement: reoperative frequency, outcome and management. J Heart Valve Dis. 2006;15:253-9.

\section{Discussion}

Dr Lamberti (San Diego, Calif). Dr Hawkins and his colleagues have reported their results for aortic or systemic semilunar valve repair in infants and children since 1991 . If we look back over the past 20 years, we can identify 2 other operations that were proposed for aortic valve disease in infants and children that have not withstood the test of time. After 1985, aortic homograft valves were generally available for use in infants and children. In addition, the general availability of homograft valves led to enthusiasm for the Ross operation as a potentially curative operation for children. At the meeting of this association in June 1992 in Kauai, Hawaii, Dr David Clarke reported on his extensive experience with aortic valve homografts in young patients. Dr Clarke reported that cryopreserved aortic valve homografts degenerated rather quickly in infants and children less than 3 years of age. For many of us the Ross operation seemed to offer an excellent option for the treatment of important aortic valve disease in infants, children, and young adults. Mid- to long-term follow-up of patients undergoing the Ross operation has not supported the concept that replacing the aortic valve with the native pulmonary valve with the technique of root replacement is a durable substitute for the aortic valve. Today the surgeon confronted with a severe case of systemic semilunar valve insufficiency has no ideal option for treatment, particularly in infants and small children. Although the neonatal Ross operation can save the life of an infant, the patient will face multiple reoperations on the right ventricular outflow tract and the possibility that late replacement of the aortic graft will be required.

Dr Hawkins' data indicate that repair and re-repair can be accomplished with an extremely low risk of mortality. The univariate analysis of risk factors leading to reintervention does not help us much in determining when repair is more appropriate than replacement. The results for repair of nontrileaflet anatomic aortic valves are encouraging and suggest that the group from Utah have a knack for this type of surgery. Other reports in the literature do not indicate that repair for nontrileaflet aortic valves is guaranteed to be successful. I have several questions.

In the "Discussion" of the article, the authors indicate that important post-repair insufficiency was not a predictor of late intervention because no patient left the operating room with significant residual aortic insufficiency. We know how many patients underwent a repair. I think it would help if we knew how many patients entered the operating room with the surgeon intending to repair but left the operating room with a valve replacement. Comparison of these 2 groups of patients might shed some additional light on the decision-making process of repair versus replacement.

Dr Hawkins. I think that is an excellent question. Unfortunately I do not have the exact answer for you. I think that the answer probably has changed between the beginning of this study and today. I think 10 or 15 years ago that child would have been much more likely, the cases that I intended to repair; first of all I did not go into the operating room 15 years ago intending to repair that many valves. Now I do, so that has changed. I think 15 years ago I would have been more likely to replace the valve, although the Ross procedure, at least in Utah, did not really come into being until about 1994. The options were few, so we probably would have replaced it, but it would have been a mechanical valve at that point in time. I would say today this is a long answer to a short question; probably I would say $60 \%$ to $70 \%$ of the patients who enter the operating room with the intention to repair, maybe even higher, leave with a repair. Very infrequently do I replace the valve, and I think that the reason for this all to evolve, for me anyway, is the old adage that necessity is the mother of invention. Just as you mentioned, an infant with truncus arteriosus and bad insufficiency, I mean what choice is there other than a homograft to replacement and condemn that child to multiple operations. That's a long answer, but I would say probably the majority of them leave with the repair at this point in time, in 2006.

Dr Lamberti. How do you decide whether to do subcommissural annuloplasty or a circumferential annuloplasty? Is it based totally on the size of the patient?

Dr Hawkins. No. It is based on how close to the normal size of the annulus that the annulus is. So if it is 2 or $3 \mathrm{~mm}$ bigger than what the annulus should be, then I use the subcommissural, and clearly in the small children that is usually what is used. In the circumferential I use an annulus that appears to be normal, al- 
though I've used it in a few small children, and this really is not in the article I don't think, but I've used an absorbable suture, taken this from an article that I heard from Switzerland in which they were using a polydioxanone ring for the mitral valve in children with rheumatic fever in Northern Africa. I have used polydioxanone sutures, circumferential polydioxanone sutures, and I have no idea how that turns out.

Dr Lamberti. That is in the article. You did not use any homograft valves in the patients who came for replacement. Do you use aortic homograft valves in the aortic position at your institution?

Dr Hawkins. No. I have in the past but not for the last 5 years.

Dr Lamberti. Do you create stenosis with your subcommissural annuloplasty? It looked to me like the example that you presented had a turbulence during systole.

Dr Hawkins. That particular patient did not have a subcommissural annuloplasty. This was a patient with rheumatic fever who had a trileaflet valve and a cusp extension. I think that does create some mild stenosis, and I think Chris Calderone and his group from Toronto presented an article at the Society of Thoracic Surgeons this year demonstrating that the little bit of stenosis you get with a 3-leaflet augmentation is not really of any consequence long term.

Dr Lamberti. Finally, how should we interpret the data? Your results in 18 patients aged less than 4 years are excellent, particularly in comparison with other alternatives. Should we always try to repair the functional aortic valve when a Ross procedure is a realistic option, or is it better to postpone the Ross operation if the repair seems reasonable?

Dr Hawkins. That's a really hard question. I guess it has changed for me, John, over the last few years. I now enter the operating room with the intent to repair, and the Ross is a secondary backup even in the small children. It is a judgment call. I tell the parents this: My decision to repair is based on whether I believe that when I finish I'm going to have a result that is going to last longer than the Ross. If I do, then I repair it. If I don't, then I do a Ross.

Dr Clarke (Denver, Colo). John, I enjoyed your presentation very much. You had 5 patients who had quadricuspid truncal valves in your series, but I really did not see any specific reference to the technique that you used to handle these. As you know, the group in Chicago has championed the technique of leaflet resection with or without coronary reimplantation. I'm curious as to how you handle these valves.

Dr Hawkins. I have not used the Chicago technique. I've been nervous to chop a valve up and try to put it back together. My approach on those valves that I did not include, I put those under cusp repair. What I have generally done is to take a quadricuspid valve and make it into a tricuspid valve. I try to pick the leaflet that I think is prolapsing or is the cause of the insufficiency, and I think that is best determined on the short-axis view of your TEE, you can generally tell where that is, and try to bolster it and make it work. 